\title{
A Complex Chromosomal Rearrangement with Formation of a Ring 4
}

\author{
MARTIN BOBROW, LILIAN F. JONES, and G. CLARKE \\ From MRC Population Genetics Unit, Oxford; and Princess Margaret Hospital, Swindon
}

Ring chromosome formation, though uncommon, is now a well-recognized cause of congenital anomalies in man. On the basis of early work in other organisms, it is assumed that ring formation involves a break in each arm of the chromosome, with reunion to form a centric ring and an acentric fragment. The latter is subsequently lost, and the phenotype results essentially from deletion of this chromosomal material, complicated by duplications and deficiences arising in somatic cells due to the mitotic instability of ring chromosomes (McClintock, 1938).

\section{Case Report}

The patient (A.P.) is the only child of healthy parents. The mother was 24 and the father 27 years old at the time of his birth. There is no relevant family history. Because of severe pre-eclamptic toxaemia, labour was induced at about full term. The infant was mature but small, weighing only $1670 \mathrm{~g}$; the placenta appeared healthy but weighed only $396 \mathrm{~g}$.

The patient is now nearly 4 years old. His facial appearance at age 2 is shown in Fig. 1 . The clinical picture is dominated by extreme growth retardation (Fig. 2). At age 3 years 9 months, he was $75 \mathrm{~cm}$ tall, weighed $6.6 \mathrm{~kg}$, and had a head circumference of $40 \mathrm{~cm}$. The head is reasonably in proportion to his body size. The blood urea has been slightly raised since birth, reaching a maximum of $66 \mathrm{mg} / 100 \mathrm{ml}$. Intravenous pyelography did not demonstrate any renal pathology, and as the urea level has not been rising, further investigations have not been pursued.

As an infant he was somewhat hypotonic, but no abnormalities of the central nervous system were noted. At about 1 year of age, he started having isolated convulsions, occurring every 2 to 3 months. These are now controlled with a small dose of phenobarbitone. The developmental quotient has been assessed on two occasions at about 50 on the Griffiths scale (Dr M. Turnbull). His bone age is grossly retarded; at $3 \frac{1}{2}$ years no carpal ossification centres were seen, but there was early ossification of proximal phalangeal epiphyses.

Minor abnormalities included hypertelorism; bilateral

Received 8 May 1970. epicanthus; some degree of micrognathia (which has become less evident as the patient grows older); an overhanging upper lip; slightly low set ears; widely spaced nipples; and marked sacral skin dimples. The right testis is retractile, but the left testis has never been palpated. The external genitalia are otherwise normal. There is no evidence of congenital heart disease. The cry has never been unusual or 'mewing'.

Dermatoglyphs. There is slight clinodactyly of the 5th digit on both hands. A transverse palmar crease is present on the left only. A b-c loop pattern is present bilaterally, but there are no thenar or hypothenar patterns. The dermal ridges are normally developed. Atd angles are $72^{\circ}$ (left) and $57^{\circ}$ (right). The left 4th digit has a whorl pattern, but all other digits have ulnar loops; an accurate ridge count could not unfortunately be made, but 7 digits counted all showed a pattern size of 9-10, except the whorl, which counted at 12 . The total ridge count would probably therefore have been in the vicinity of 100 . Both hallucal areas show large distal loops.

Cytology. Chromosome analyses were performed on 72 -hour cultures of peripheral blood. In over $90 \%$ of cells, a member of the B group has been replaced by a ring chromosome; all cells were lacking a chromosome 17-18, which was replaced by a larger metacentric chromosome (Fig. 3). 113 metaphases of acceptable quality were analysed with regard to the form of the ring (Table 1). Of the two cells with 46 chromosome and no ring, one had an extra $\mathrm{C}$ group member and one a small metacentric fragment. There is therefore no evidence of a normal cell line. Three cells contained dicentric rings, approximately double the size of the usual ring form; apart from this, there was no obvious variation in ring size from cell to cell.

Inspection of 1433 consecutive metaphases revealed 20 tetraploid and one octoploid nucleus, a rate of polyploidy which is not abnormal in our laboratory. Analysis of the ring form in these polyploid nuclei is presented in Table II. The cells described as showing a 'pulverized' ring contained a fragmented chromatin mass similar to that described by Gripenberg (1967).

Micronuclei, as described by Turner et al (1962), were present in $\mathbf{8}$ of $\mathbf{3 0 0}$ interphase nuclei examined, as compared with $1.1 \%$ in 3 control cultures. This difference just fails to reach significance at the $5 \%$ level.

Preparations made without colchicine were used for 

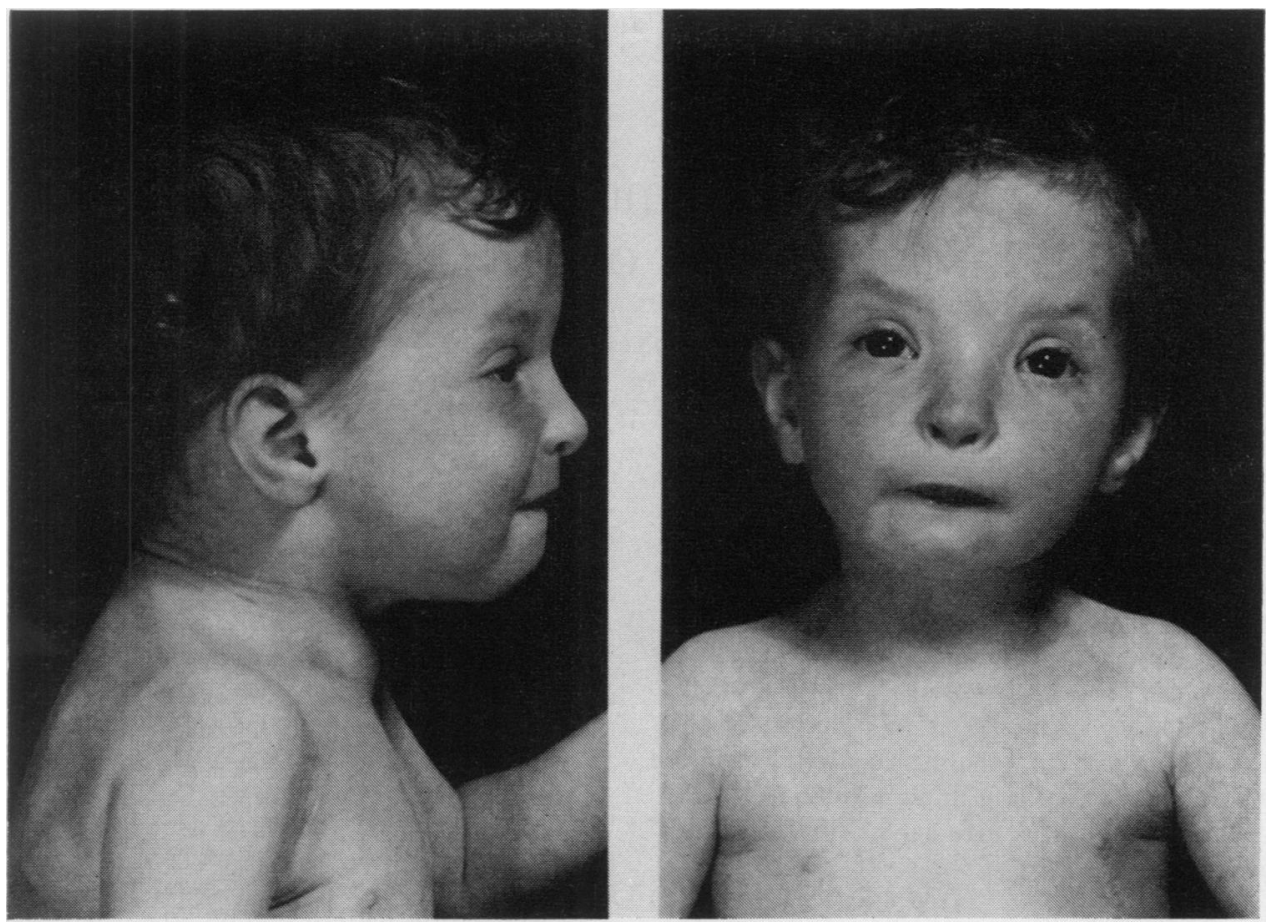

Fig. 1. Patient aged 2 years.

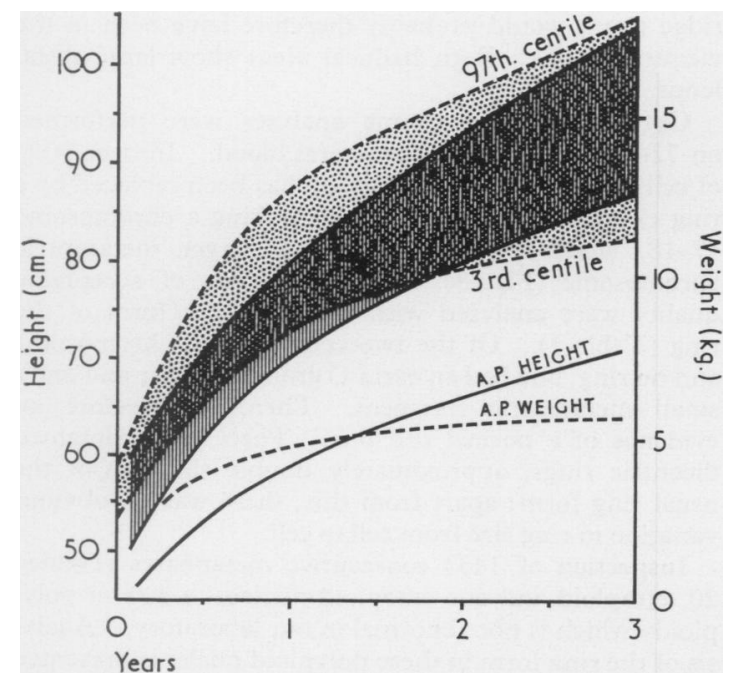

FIG. 2. Length $(-)$ and weight (--) of the patient. Hatched areas indicate the $3 \%-97 \%$ ranges of normal are indicated by the vertically hatched area (height) and the stippled area (weight).

analysis of the behaviour of the ring at anaphase. Thirtyfive suitable cells in anaphase and telophase were examined. Sixteen of these showed the presence of a double chromatin bridge (Fig. 4), interpreted as representing either a dicentric ring chromosome or interlocked monocentric daughter ring chromosomes. Examples of both types of bridge were seen, but the proximity of the two arms of the bridge in these preparations made it impossible in most cells to differentiate satisfactorily between interlocked rings and dicentric rings with a $180^{\circ}$ twist in them.

The formation of these bridges corresponds with the behaviour previously described for ring chromosomes in maize (McClintock, 1938) and human tumour cells (Levan, 1956). The rate of bridge formation, however, exceeds that described for even the largest rings in maize. Anaphase bridges have also been described in non-malignant human cells containing a ring $\mathrm{C}$ (Turner et al, 1962). It is likely that they arise as a result of sister-chromatid exchange (Lejeune, 1968). The high rate of bridge formation in the present case correlates well with the high proportion of tetraploid cells which contain dicentric rings. The normal frequency of polyploid cells suggests that the bridge does not seriously inhibit separation of daughter nuclei. The presence of apparently healthy cells missing the ring would argue against the hypothesis that a rigid selection is operating to remove immediately all products of cell division in which bridges are formed. We therefore conclude that this ring chromosome is forming a chromatin bridge in a high proportion of cellular divisions, and that breakage and rejoining of the ring is occurring frequently. The absence of gross size variation of the ring suggests that 


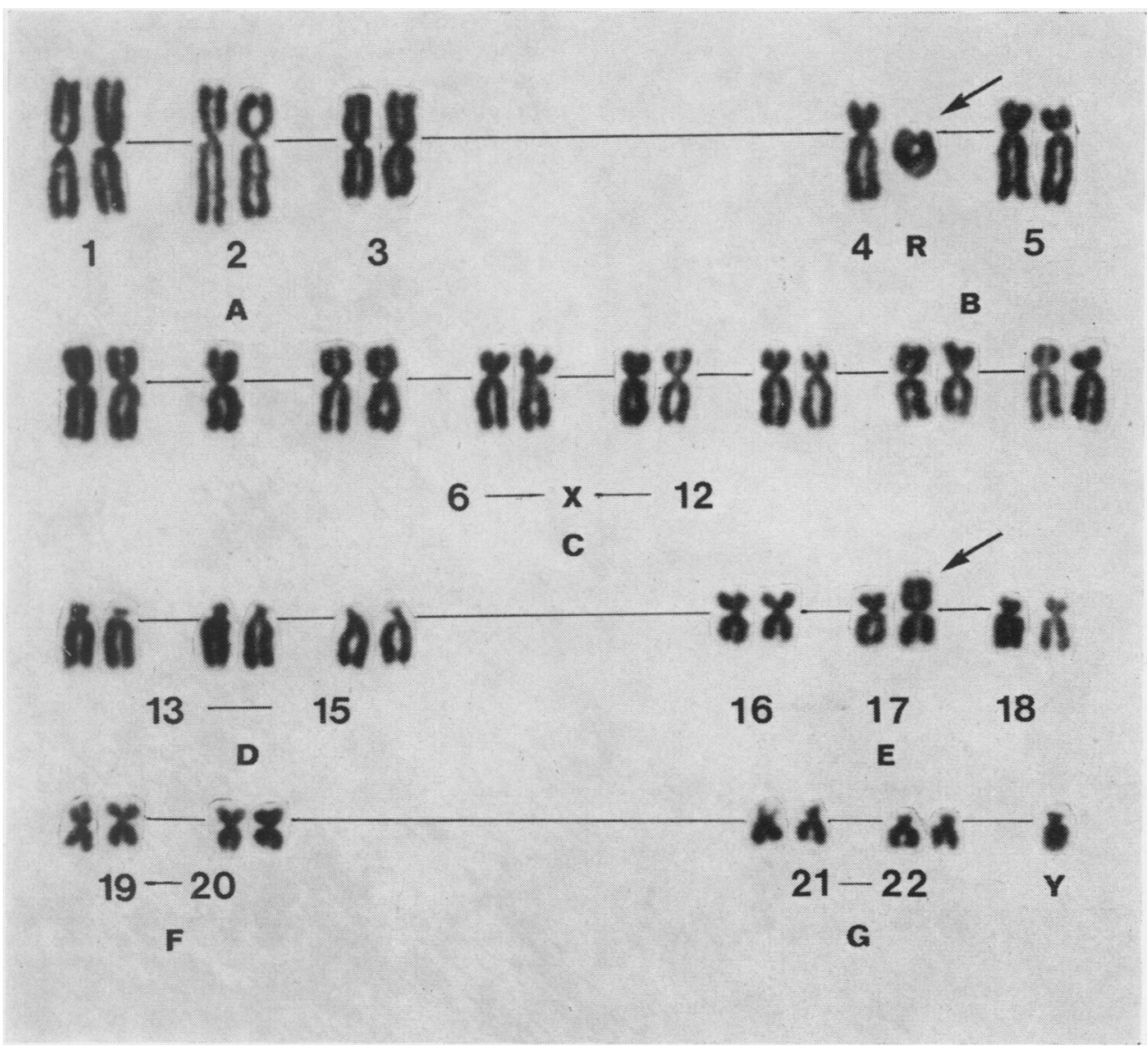

Fig. 3. Karyotype of the propositus.

TABLE I

RING FORM IN DIPLOID CELLS

\begin{tabular}{|c|c|c|c|c|c|c|}
\hline $\begin{array}{l}\text { Chromosome number } \\
\text { Ring } \\
\text { No. of cells }\end{array}$ & $\underset{103}{46}$ & $\underset{3}{46}$ & $\underset{2}{46}$ No ring & $\underset{4}{45}$ No ring & $\stackrel{45}{\text { Monocentric }}$ & $\begin{array}{c}\text { Total } \\
113\end{array}$ \\
\hline
\end{tabular}

TABLE II

RING FORM IN TETRAPLOID CELLS

\begin{tabular}{l|c|c|c|c|c|c|c|c|c|c|c|}
\hline Ring & 1 monocentric & 1 dicentric & 2 monocentrics & 2 dicentrics & Pulverized & No ring & Not analysable & Total \\
No. of cells & 1 & 4 & 2
\end{tabular}

some regularizing mechanism does exist, perhaps determining the likely sites of ring breakage.

Instances in which the bridge did not part would account for the small proportion of diploid cells missing a ring, and those containing a dicentric ring. By and large, however, we are impressed by the apparent stability of this ring as viewed at metaphase, in light of the high frequency of anaphase bridge formation. Similar behaviour has been observed in another large ring at present under study in this laboratory. Further investigations into this phenomenon are in progress.

Cells incubated with tritiated thymidine were examined autoradiographically, 26 informative metaphases being found. These regularly showed one $B$ group 


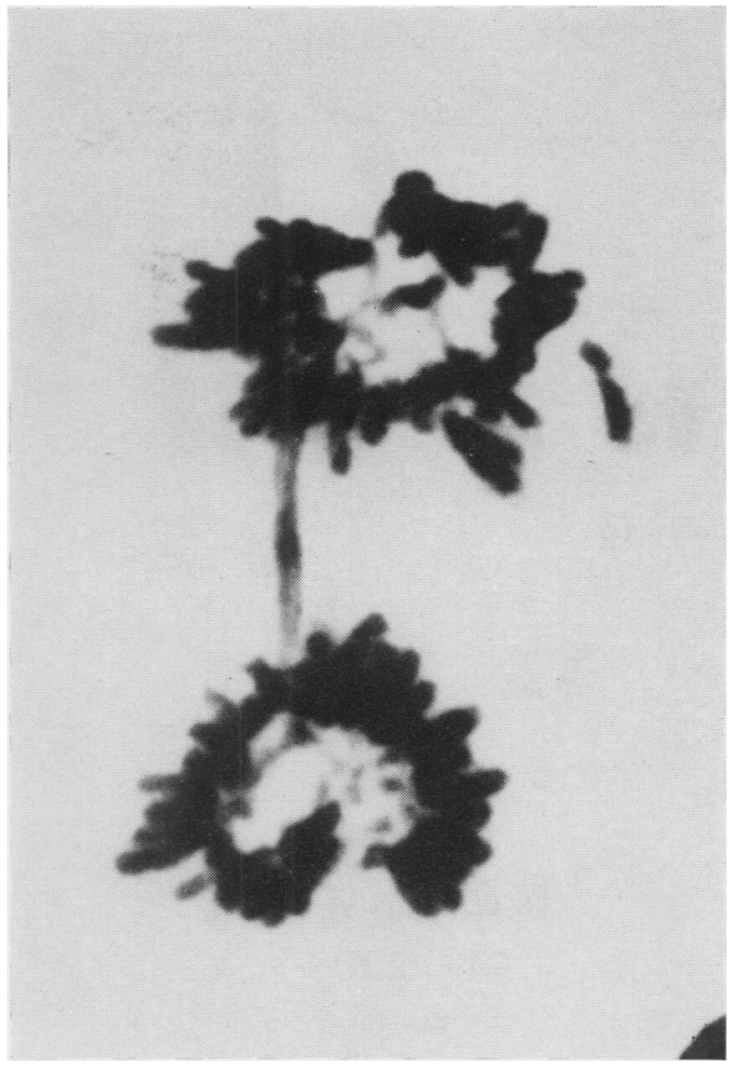

Fig. 4. A representative cell, showing double chromatin bridge at anaphase.

chromosome heavily labelled on the long arms, the other two B chromosomes being either unlabelled or labelled predominantly over the short arms (Fig. 5). This labelling pattern suggests that the missing B group chromosome, which partook in the ring formation, was a No. 4. The ring itself was always heavily labelled. Autoradiographic identification of the $\mathbf{E}$ group chromosome involved could not be satisfactorily accomplished.

Two skin cultures were attempted at an interval of about one year. In both instances, growth was very slow in starting and proceeded unusually slowly. When chromosome preparations could eventually be made, the cultures were found to be grossly aneuploid. There was no trace of the ring chromosome. Whether this is an indication of true mosaicism or whether the ring is being excluded under cultural conditions, cannot be proven. It is our opinion that the latter is the more likely explanation.

Both parents are chromosomally normal.

Genetic markers. The patient and both parents were typed for the following marker loci by $\mathrm{Dr} E$. Robson: Hp; Tf; AcP; PGM 1; AK; Ada; and peptidases $A, B, C$, and $D$. The blood group loci determined were: ABO; Rh; MNS; P; Lu; K; Fy; Jk. No anomalous inheritance was noted, and the patient was heterozygous for only $3 \mathrm{loci}$, viz. haptoglobin, acid phosphatase, and MNS (genotype at these loci: $\mathrm{Hp} 2 \cdot 1$, AcP BA; MS/Ms).

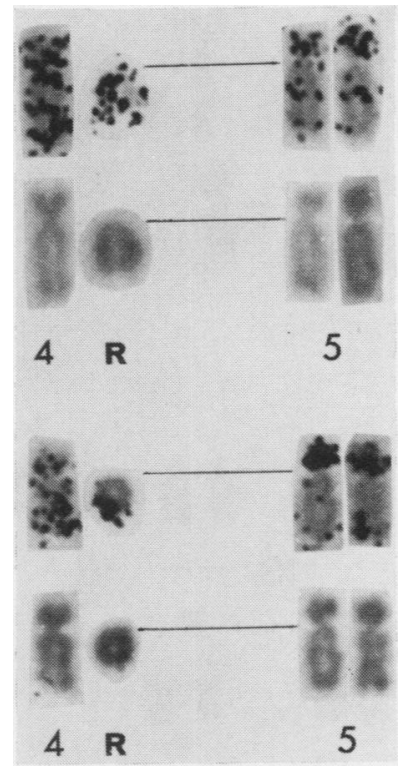

FIG. 5. B group chromosomes from 2 illustrative cells; top row showing autoradiographs and bottom row after removal of silver grains.

\section{Discussion}

The simplest interpretation of the chromosomal anomaly in this case involves 3 chromosomal breaks, in both arms of the No. 4 and the short arm of an $E$ group chromosome. Reunion would give a ring 4, and a translocation $\mathrm{Ep}+$ chromosome; acentric fragments of part of a $B$ and part of an $E$ group chromosome would have been lost (Fig. 6). The result of this interchange would be a small deletion of either the short or the long arm of chromosome No. 4, and a deletion of short arm material from either No. 17 or No. 18.

The anomaly Ep - has been described (reviewed by Polani, 1969). The present case does not bear any striking resemblance to those with the simple deletion, though there are certain non-specific symptoms such as hypertelorism, epicanthus, and mental retardation in common. Deletion of the long arm of No. 4 has also been described (Ockey et al, 1967), with a clinical presentation quite different from the present case. Several cases of No. 4 short arm deletions are on record, and they appear 


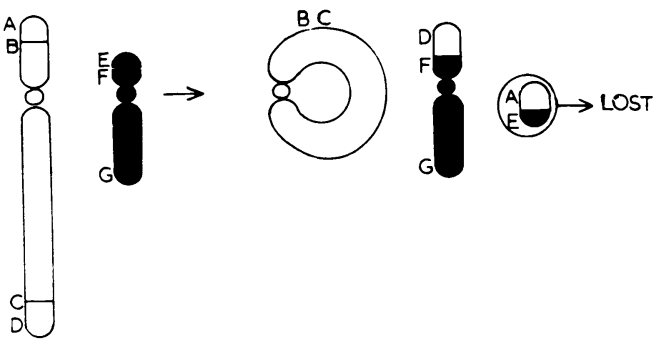

Fig. 6. Suggested interpretation of the chromosomal anomaly.

to have some clinical features in common (Miller, Warburton, and Breg, 1969).

Four previous cases of ring B chromosomes have been recorded (Rohde and Tompkins, 1965; Steele et al, 1966; Faed, Stewart and Keay, 1969; Carter, Baker, and Hayman, 1969). The first two showed the clinical characteristics of the 'cri-du-chat' syndrome, and were therefore interpreted as No. 5 rings. The case of Faed $e t$ al was born at 43 weeks, weighing $1480 \mathrm{~g}$. It had very severe congenital malformations and died shortly after birth. The case described by Carter et al showed a phenotype compatible with that described for $4 p-$, and it was therefore suggested that the ring was of No. 4 origin, but autoradiography was not carried out.

Certain clinical features of the present case are compatible with those described for $4 \mathrm{p}-$ : low birthweight, statural and psychomotor retardation, hypertelorism and epicanthus, micrognathia and an overlapping upper lip, sacral dimples, maldescent of the testes, seizures, and marked delay in ossification of the carpal bones. There is an absence of midline facial defects, scalp defects, ptosis, colobomata, and hypoplastic dermal ridges. In view of the unknown amount of No. 4 deleted, and the concomitant deletion of $\mathbf{E}$ group material, the clinical picture of our case seems reasonably compatible with that described for deletion of the short arm of No. 4. We, therefore, tentatively conclude that such a deletion has occurred, and that the extra material translocated onto the 17-18 originated from the long arm of No. 4.

\section{Summary}

A case is described of severe proportional dwarfism and mental retardation with minor congenital abnormalities, associated with a complex chromosomal rearrangement involving chromosome No. 4 and a 17-18 chromosome. The karyotype is interpreted as $46, \mathrm{XY}, 4 \mathrm{r} / 46, \mathrm{XY}, 4 \mathrm{r}, \mathrm{Ep}+$. This could have arisen as a 3-break phenomenon, with the loss of a part of the short arms of both No. 4 and a 17-18. The ring forms anaphase bridges in a significant proportion of mitoses, yet preserves an apparent stability in metaphase preparations.

\section{REFERENCES}

Carter, R., Baker, E., and Hayman, D. (1969). Congenital malformations associated with a ring 4 chromosome. Fournal of Medical Genetics, 6, 224-227.

Faed, M., Stewart, A., and Keay, A. J. (1969). Chromosome abnormalities in two cases with bilateral radial element defects. fournal of Medical Genetics, 6, 342-346.

Gripenberg, U. (1967). The cytological behaviour of a human ringchromosome. Chromosoma, 20, 284-289.

Lejeune, J. (1968). De la duplication de structures circulaires. Annales de Génétique, 11, 71-77.

Levan, A. (1956). Self-perpetuating ring chromosomes in two human tumours. Hereditas, Genetiskt Arkiv, 42, 366-372.

McClintock, B. (1938). The production of homozygous deficient tissues with mutant characteristics by means of the aberrant mitotic behaviour of ring-shaped chromosomes. Genetics, 23, 315-376.

Miller, O. J., Breg, W. R., Warburton, D., Miller, D. A., Firschein, I. L., and Hirschhorn, K. (1966). Alternative DNA replication patterns associated with long arm length of chromosomes 4 and 5 in the Cri-du-chat syndrome. Cytogenetics, 5, 137.

Miller, O. J., Warburton, D., and Breg, W. R. (1969). Deletions of Group-B chromosomes. In First Conference on the clinical delineation of birth defects. Birth Defects Original Article Series, 5.

Ockey, C. H., Feldman, G. V., Macaulay, M. E., and Delaney, M. J. (1967). A large deletion of the long arm of chromosome No. 4 in a child with limb abnormalities. Archives of Disease in Childhood, 42, 428-434.

Polani, P. E. (1969). Autosomal imbalance and its syndromes, excluding Down's. British Medical Bulletin, 25, 81-92.

Rohde, R. A. and Tompkins, R. (1965). 'Cri-du-chat' due to a ring-B(5) chromosome. Lancet, 2, 1075-1076.

Steele, M. W., Breg, W. R., Eidelman, A. I., Lion, D. T., and Terzakis, T. A. (1966). A B-group ring chromosome with mosaicism in a newborn with cri-du-chat syndrome. Cytogenetics, 5, 419-429.

Turner, B., Jennings, A. N., den Dulk, G. M., and Stapleton, T. (1962). A self-perpetuating ring chromosome. Medical fournal of Australia, 2, 56-58. 